\title{
Entomoftoromicose (zigomicose) causada por Conidiobolus coronatus em Mato Grosso (Brasil): relato de caso
}

\author{
Entomophthoramycosis (zygomycosis) caused by Conidiobolus coronatus \\ in Mato Grosso (Brazil): case report
}

\author{
Tomoko Tadano ${ }^{1}$, Neiva P. Paim ${ }^{1}$, Marcia Hueb ${ }^{1}$ e Cor Jésus F. Fontes ${ }^{1}$
}

\begin{abstract}
RESUMO
Zigomicoses são micoses subcutâneas causadas por fungos do solo, que geralmente manifestam-se como uma infiltração granulomatosa crônica da submucosa nasal, estendendo-se para o tecido subcutâneo e pele da face. Descreve-se aqui o primeiro caso de zigomicose nasofacial causada pelo Conidiobolus coronatus, ocorrendo em Mato Grosso, Brasil.
\end{abstract}

Palavras-chaves: Entomoftoromicose. Zigomicose. Conidiobolus coronatus. Mato Grosso.

\begin{abstract}
Zygomycosis is a subcutaneous mycosis caused by soil fungi, such as Conidiobolus coronatus. In general, the main clinical manifestation is a chronic rhinofacial tumor. We report the first case of zygomycosis (entomophthoramycosis) caused by Conidiobolus coronatus, occurring in Mato Grosso, West Brazil.
\end{abstract}

Key-words: Entomophthoramycosis. Zygomycosis. Conidiobolus coronatus. Mato Grosso.

Zigomicoses são micoses subcutâneas causadas por fungos das ordens Mucorales e Entomophthorales. Dentro dessa última, os fungos das famílias Entomophthoraceae e Basidiobolaceae têm importância médica, sendo causadores de zigomicoses (entomoftoromicose por Conidiobolus coronatus e C. incongruus; basidiobolomicose por Basidiobolus ranarum) ${ }^{47}$.

Esses fungos são comumente encontrados no solo e nas folhas secas do chão, sendo a infeç̧ão decorrente da implantação de esporos inalados, juntamente com partículas do solo, sobre a mucosa nasal. Sabe-se que in vitro o fungo é capaz de produzir várias enzimas tais como elastases, esterases, colagenases e lípases, as quais podem estar envolvidas na patogênese da infecção ${ }^{3}$. A entomoftoromicose causada por C. coronatus manifesta-se clinicamente como um infiltração granulomatosa crônica da mucosa nasal, estendendo-se para 0 tecido subcutâneo e pele da face contígua, sem delimitação de seu crescimento. Essa expansão tumoral produz sintomas como obstrução nasal e dor local, sendo freqüente a sinusite bacteriana, conseqüente ao processo obstrutivo presente. Chama a atenção, entretanto, a grande frequiência de deformidade facial, resultante de infiltração e edema da região $0^{34}$. 0 diagnóstico é geralmente confirmado por cultura e pela visualização microscópica do fungo em material obtido da lesão. Histopatologicamente, a doença se caracteriza por infiltrado granulomatoso do tecido subcutâneo, contendo material eosinofílico hialino, no qual são visualizadas hifas grandes, não septadas ( ou raramente septadas) de C. coronatus ${ }^{4}$.

Descreve-se aqui o primeiro caso de zigomicose nasofacial causada por C. coronatus em Mato Grosso.

\section{RELATO DO CASO}

JASF, 37 anos, pedreiro, residente em Sinop-MT, desde 1978. Relatou trauma facial com fratura de osso nasal em 1992. Há 2 anos vem apresentando obstrução nasal e epistaxe discreta e esporádica. Evoluiu com aumento progressivo de nódulos subcutâneos duros e pouco dolorosos no dorso do nariz e nas regiões paranasal e frontal. Durante esse período, foi submetido a exaustivo processo de investigação, incluindo biópsia da lesão em região infra-orbitária direita, com diagnóstico de processo inflamatório crônico granulomatoso tipo corpo estranho; porém sem conclusão etiológica. Recebeu vários tipos de tratamento empíricos, sem contudo apresentar melhora. Recentemente,

1. Núcleo de Estudos de Doenças Tropicais de Mato Grosso da Faculdade de Ciências Médicas da Universidade Federal de Mato Grosso, Cuiabá, MT, Brasil Endereço para correspondência: Dr. Cor Jésus Fernandes Fontes. Rua Presidente Wenceslau Bras 355, Morada do Sol, $78043-508$ Cuiabá MT, Brasil. Tel: 5565 642-5149 
procurou o Hospital Universitário da UFMT referindo obstrução nasal e dificuldade para respirar. Apresentava deformidade facial e nasal, com infiltração do subcutâneo e pele das regiões frontal, malar, dorso e asas do nariz, com apagamento do sulco nasolabial ( Figura 1). Havia também hiperemia e hipertrofia dos cornetos nasais. A tomografia computadorizada da face revelou apenas espessamento de partes moles, sem acometimento ósseo.

Foi solicitado para revisão 0 material obtido em biópsia anterior. Os novos cortes histológicos corados pela hematoxilinaeosina evidenciaram inflamação crônica granulomatosa, com presença de fungos envoltos por abundante material granuloso e eosinofílico com disposição radiada, característica do fenômeno de Splendore-Hoeppli. Notou-se ainda infiltração por eosinófilos e plasmócitos, além de intensa fibrose. Após impregnação pela prata (método de Grocott) foi possível visualizar hifas largas e com escassos septos ( Figura 2).

Ao exame micológico direto observaram-se raras hifas largas, não septadas. Após semeadura em agar Sabouraud-dextrose 2\%, houve crescimento de colônia plana e glabra, de tonalidade creme (Figura 3A), e rodeada por várias pequenas colônias satélites. À microscopia do cultivo em lâmina em agar batata foram visualizados conídios esféricos, com papilas basais de bordas arredondadas (Figura 3B). 0 achado de conídios vilosos com esterígmas (microconidióforos) radiados (Figura 4A) econídios multiplicativos (Figura 4B) confirmou tratar-se de infecção por C. coronatus. Além disso, registrou-se a presença de hifas largas, não septadas, com inclusão granular, algumas delas septadas (Figura 4A) .

0 paciente encontra-se em tratamento com cetoconazol + solução saturada de iodeto de potássio, apresentando resposta satisfatória das lesões.

\section{DISCUSSÃ0}

Conidiobolus coronatus (Costantin) Batko, 1964, é um fungo saprófita do solo, que pode parasitar espécies de artrópodos, tais como insetos e aranhas. A infecção no homem ocorre, em geral, na ausência de imunodepressã $0^{58}$.

A entomoftoromicose causada por C. coronatus é infecção rara e cujo acometimento rinofacial foi primeiramente descrito em $1965^{6}$. Acomete principalmente lavradores masculinos, entre 40-60 anos de idade ${ }^{3}$. É micose pouco relatada no mundo, sendo descrita principalmente nas regiões de florestas tropicais da África e na Amazônia. № Brasil, já foi descrita principalmente nos estados do Nordeste e Pará ${ }^{25}$, sendo este 0 primeiro relato de ocorrência da doença em Mato Grosso.

Em geral a infecção apresenta grande dificuldade diagnóstica, por não ser suspeitada em sua fase inicial. Assim, a maior parte dos casos é diagnosticada nos estágios avançados da doença ${ }^{7}$. 0 paciente aqui mostrado ilustra esse fato, pois teve a sua infecção provavelmente na ocasião do traumatismo nasal, ocorrido cerca de 10 anos antes do diagnóstico.

0 atraso no diagnóstico, e conseqüente maior extensão da lesão, tornam 0 tratamento mais difícil, em função de baixa resposta terapêutica. A solução saturada de iodeto de potássio
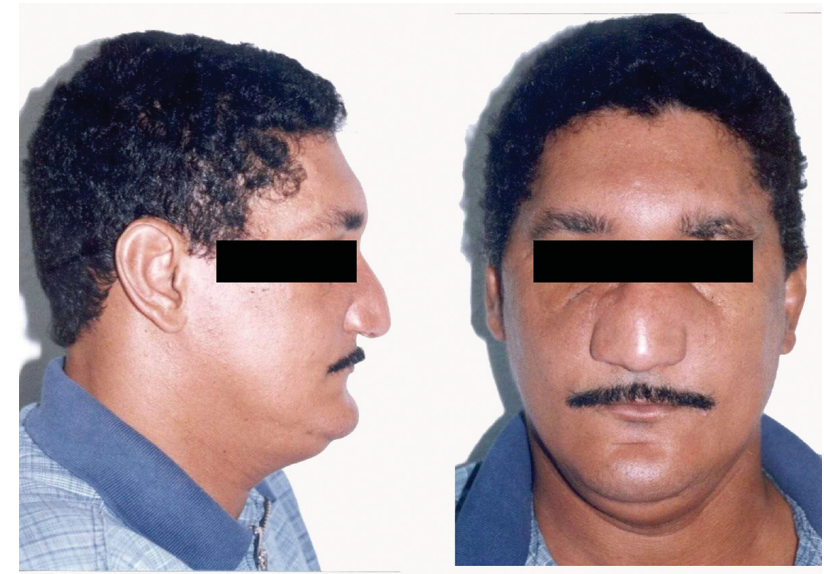

Figura 1 - Alterações topográficas da conformação facial do paciente, mostrando infiltração e deformidade das regiões frontal, zigomática e nasal. Cicatriz infra-orbitária direita de biópsia realizada anteriormente.

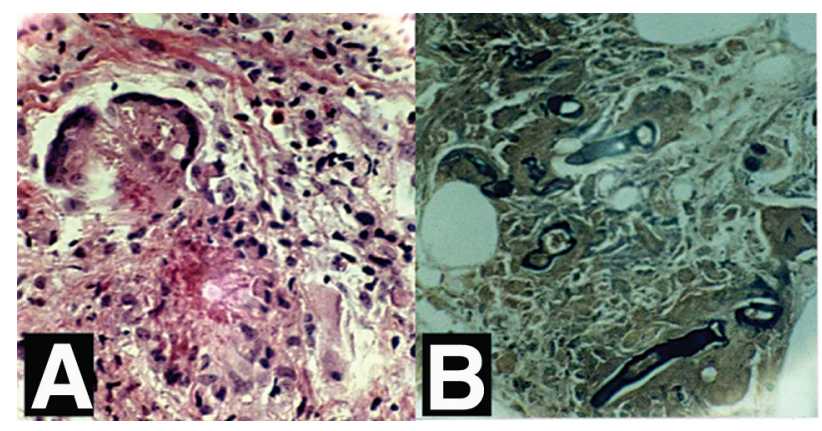

Figura 2 - Aspecto histopatológico de tecido tumoral obtido por biópsia de pele e subcutâneo de região infra-orbitária direita mostrando: (A) inflamação crônica granulomatosa, com presença de fungos envoltos por material granuloso e eosinofílico com disposição radiada e intensa fibrose (hematoxilina-eosina 1000X); (B) presença de hifas largas e com escassos septos, após impregnação pela prata (método de Grocott 1000X)

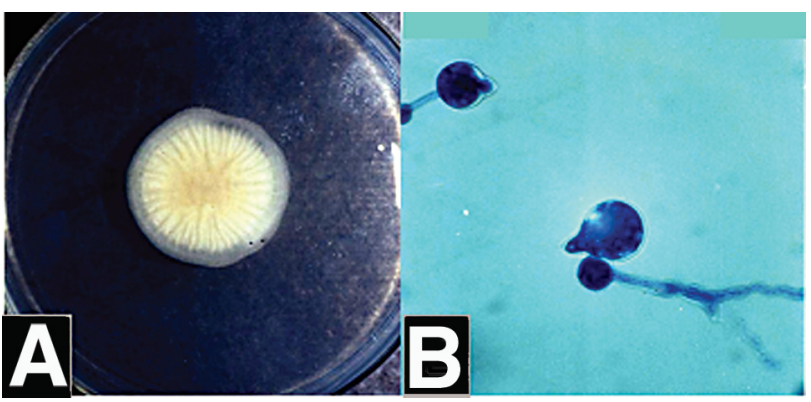

Figura 3 - (A) Aspecto plano e glabro da colônia de C. coronatus, de tonalidade creme em agar Sabouraud-dextrose 2\%; (B) Conídios esféricos, com papilas basais de bordas arredondadas, à microscopia de microcultivo em lâmina em ágar batata, corados com lactofenol azul-algodão (1000X).

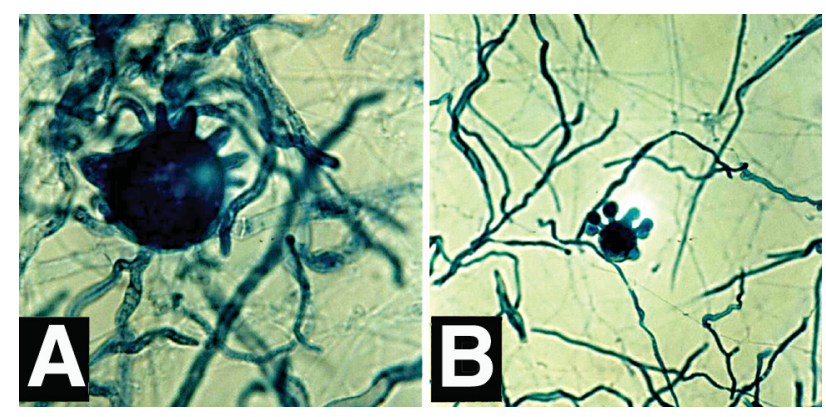

Figura 4 - Microscopia de cultivo de C. coronatus em lâmina em ágar batata, corado com lactofenol azul-algodão, mostrando: (A) Conídios vilosos com esterígmas (microconidióforos) radiados (1000X); (B) conídios multiplicativos típicos de C. coronatus (400X). 
tem sido usada principalmente na África, com resultados satisfatórios ${ }^{1}$. Recentemente, relatos de resposta aos imidazólicos e a outros antimicóticos têm surgido esporadicamente na literatura ${ }^{78}$.

Após 6 meses de tratamento regular com cetoconazol + solução saturada de iodeto de potássio, o caso aqui relatado tem mostrado progressiva regressão das lesões, indicando resposta adequada ao tratamento. Entretanto, longo tempo de seguimento será necessário para afastar a possibilidade de recidiva, a qual é freqüentemente descrita para qualquer tipo de tratamento desta micose ${ }^{4}$.

\section{REFERÊNCIAS BIBLIOGRÁFICAS}

1. Bandeira V, Lascet IG. Zigomicose. In: Talhari S, Neves RG (eds) Dermatologia Tropical, São Paulo, Medsi, p. 191-202, 1995.

2. Costa AR, Porto E, Pegas JR, Reis VM, Pires MC, Lacaz CD, Rodrigues MC, Muller H, Cuce LC. Rhinofacial zygomycosis caused by
Conidiobolus coronatus. A case report. Mycopathologia 115:1-8, 1991.

3. Gugnani HC. Entomophthoramycosis due to Conidiobolus. European Journal of Epidemiology 8:391-396, 1992.

4. Kwon-Chung KJ, BennettJE. Zygomycosis. In: Kwong-Chung KJ, BennettJE (eds), Medical mycology, Lea \& Febiger, Pensylvania, p. 447-463,1992.

5. Moraes MA, Arnaud MVC, Almeida MMR. Zigomicose nasofacial no Estado do Pará: registro de dois casos. Revista da Sociedade Brasileira de Medicina Tropocal 30:329-331, 1997.

6. Mukhopadhyay D, Ghosh LM, Thammayya A, Sanyal M. Entomophthoramycosis caused by Conidiobolus coronatus: clinicomycological study of a case. Auris Nasus Larynx 22:139-142, 1995.

7. Restrepo A. Treatment of tropical mycoses. Journal of the American Academy of Dermatology 31:91-102, 1994.

8. Valle ACF, Wanke B, Lazera MS, Monteiro PCF, Viegas ML. Entomophthoramycosis by Conidiobolus coronatus. Report of a case successfully treated with the combination of itraconazole and fluconazole. Revista do Instituto de Medicina Tropical de São Paulo 43:233-236, 2001. 